\title{
A DATAÇÃO DE HOMERO NA FINLÂNDIA: KALEVALA, O ÉPICO SEPARATISTA.
}

\author{
Áureo Lustosa Guérios Neto ${ }^{1}$
}

\section{Introdução}

Esse é um trabalho sobre Homero. Apresentarei aqui um quadro ilustrativo do problema homérico conforme apresentado por Havelock em Prefácio a Platão e por Lord em The Singer of Tales e tentarei situar o épico finlandês, o Kalevala, em uma das linhagens que esses estudiosos discutem.

\section{O problema homérico}

De certa forma o problema homérico é uma conquista recente. Embora certas discussões relacionadas ao tema já existissem desde o século XVIII foi somente em 1933 após a intervenção de Carpenter que o problema se estabeleceu definitivamente. Segundo Havelock ${ }^{2}$, Carpenter corrigiu algumas autoridades anteriores no que concerne à datação da escrita na Grécia antiga e deslocou sua criação/assimilação do século XII ou XIII a.C., onde ela estava confortavelmente assentada, para o século VIII, mais especificamente "cerca de 720-700". Havelock discorre brevemente sobre a longa discussão que se seguiu e enumera uma série de estudos que apontavam em direção de uma ou de outra datação. $\mathrm{O}$ caso é que, embora a sugestão de Carpenter tenha sido bastante questionada e que adendos tenham sido feitos deslocando a datação algumas décadas para trás, ela é aquela que se aceitou convencionalmente como a mais próxima da verdade.

\footnotetext{
${ }^{1}$ Graduando do curso de Licenciatura e Bacharelado em História da Universidade Federal do Paraná.

${ }^{2}$ HAVELOCK, Eric. Prefácio a Platão. Trad. Enid Abreu Dobránzsky. Campinas: Papirus, 1996. Vide a introdução da obra.
} 
O próprio Havelock dá sua contribuição à contenda ao tentar demonstrar que o conceito de 'cidadão alfabetizado' na Grécia antiga era bastante relativo ainda no século V. Os argumentos apresentados são curiosos. Ele afirma, sempre em Prefácio à Platão, que uma prova de que a alfabetização não era plena no século $\mathrm{V}$, nem mesmo entre a classe dominante, era a de que nas tragédias e nas comédias os livros e documentos escritos eram sempre objetos que despertavam desconfiança e hilaridade, respectivamente. Além disso, ele procura levantar traços de oralidade em escritos da época e seu exemplo mais feliz é o dos diálogos platônicos que, mesmo sendo texto escrito, apelam diretamente à oralidade. Ele conclui sua argumentação afirmando que um jovem que soubesse escrever apenas o próprio nome provavelmente seria considerado, na Grécia do século $\mathrm{V}$, um cidadão alfabetizado.

E foi assim, nos diz Havelock, que a contribuição de Carpenter à epigrafia criou, definitivamente, problemas ao estudioso de Homero. Pois, se Homero viveu no século IX a. C., como tradicionalmente se aceita, e se a escrita foi criada/assimilada apenas no século VIII, como seus poemas podem ter sobrevivido aos duzentos anos que se colocam no caminho? Duzentos anos que podem aumentar se tomamos em consideração que a criação de uma escritura não implica, necessariamente, em uma efetiva e imediata alfabetização. Assim, é possível que mesmo após a criação de um alfabeto as obras de Homero tenham permanecido 'não-escritas' por um certo tempo. ${ }^{3}$

Albert Lord na introdução de sua obra magna, The Singer of Tales, nos oferece uma pequena síntese das discuções acadêmicas então em voga e aponta as três soluções possíveis que se colocaram diante do pesquisador de Homero naquele momento: (1) a datação de Homero deveria ser deslocada para algum momento em que fosse possível um convívio com a escrita; (2) a datação da escrita deveria ser deslocada para algum momento anterior à datação usual da vida de Homero; ou (3) manter a datação de Homero no século nono e a

${ }^{3}$ Idem. 
da escrita no século oitavo assumindo um conseqüente período de transmissão oral da obra homérica.

Lord se posiciona logo em seguida, apresenta seus argumentos e descarta as duas primeiras opções. Segundo ele, apenas aqueles que elegeram a terceira opção deslocaram-se na direção correta. Lord dedica em seguida sua atenção a comentar como os estudiosos obordaram a preservação oral e afirma que, em um primeiro momento, a oralidade foi tratada de modo ingênuo.

Por que ingênuo? Lord responde que vários estudiosos passaram então a acreditar que os poemas poderiam ter sido repassados de geração em geração sem sofrer qualquer perda, mantendo-se intactos. Ele tenta demonstrar com sua longa dissertação sobre a poesia oral iuguslava que uma composição oral è um mecanismo vivo que permite ao bardo de tratar a matéria narrativa ao seu modo. Lord confronta, por exemplo, uma mesma canção cantada por dois bardos diversos e demonstra como cada bardo trata a canção de forma diferente. ${ }^{4}$ Certas diferenças podem ser encontradas na descrição das personagens ou de objetos. A descrição de armas, por exemplo, é particularmente flutuante e ocupa um espaço significativo na reflexão de Lord, uma vez que é um tema tão freqüente nos textos homéricos. ${ }^{5}$ Modificações no enredo podem ocorrer, mas não são tão freqüentes.

$\mathrm{O}$ estudioso tenta demonstrar como em tradições iletradas a poesia oral deve ser necessariamente um mecanismo vivo: sua existência depende da performance do bardo e cada performance tem como resultado uma composição única.

Lord afirma que quando uma composição oral é registrada por escrito ela tende a congelar-se. A partir do momento em que temos uma versão 'original', as outras versões tornam-se 'divergentes'. Assim, enquanto na tradição oral todas as variantes eram igualmente válidas, numa tradição escrita a versão 'original' ou 'canônica' passa

${ }^{4}$ LORD, Albert B. The Singer of Tales. Cambridge: Harvard University Press, 1960. Cap. 5.

${ }^{5}$ LORD, op. cit. Caps. 1 e 7. 
a ser a 'mais correta', a 'mais válida' ou a 'mais completa'. É justamente isso que Lord tem em mente quando afirma que um texto poético escrito é necessariamente definitivo e irretocável. ${ }^{6}$

É por isso que Lord diz que acreditar que os poemas homéricos tenham sido transmitidos geração após geração ao longo de duzentos anos sem sofrer mudanças é aplicar à oralidade conceitos modernos de escritura e é, portanto, um erro metodológico.

Além disso, Lord critica o fato de que, para manter-se de pé, tal linha teórica deve contar com a "memória fantástica das pessoas iletradas" e com a existência de uma linhagem de meninos prodígios capazes de decorar versos em quantidades astronômicas. Apelar para seis ou sete gerações seguidas de virtuoses que mantenham um texto imodificável é, segundo Lord, uma saída pela tangente.

$\mathrm{O}$ argumento mais forte, porém, foi guardado para o fim. Lord em suas andanças pela Iugoslávia, quando colhia material para estudo de uma tradição épica oral viva, teve a oportunidade de gravar um cantor, Zogić, cantando uma mesma canção algumas vezes: duas vezes em 1934 e uma vez em 1951. Em 1951 foi também gravada uma entrevista com Zogić na qual ele diz cantar exatamente a mesma canção em ambas as ocasiões, "palavra-por-palavra". Lord coteja essas duas versões gravadas num intervalo de dezessete anos e em quase todos os aspectos elas são iguais. No entanto, pequenas variações podem ser percebidas: eventualmente a ordem de duas palavras se inverte, uma palavra é substituída por um sinônimo ou por outra palavra que tenha o mesmo número de sílabas, o verso que

${ }^{6}$ Lord não leva em consideração a mudança que os textos escritos sofrem progressivamente quando são copiados. Sabemos que os manuscritos tendem a hereditar erros de seus copistas e que quanto mais um texto for copiado, maior será o número de erros frente ao texto de partida. Porém, essas são mudanças se dão a partir de 'pequenos acidentes' e não de diferenças de estilo ou de vontade deliberada, como acontece na tradição oral. Nenhum copista, por menos zeloso que seja, se dá ao direito de manipular a narrativa ao seu bel-prazer, mudando descrição de objetos, personagens ou até enredo, ao contrário do que ocorre na tradição oral. Assim, o trabalho dicotômico de Lord (texto escrito = imutável, texto oral $=$ mudança constante) se justifica sem maiores problemas. 
em uma versão estava por segundo pode ter trocado de lugar com o quinto ou ainda pode ter sido omitido completamente etc. Essas mudanças são módicas, mas já estão presentes em pequeno grau nos dois textos gravados no mesmo ano. Isso faz com que Lord levante a seguinte questão: se hoje um bardo que canta nos mesmo moldes de Homero canta a mesma canção duas vezes em um ano e não produz o mesmo texto palavra-por-palavra, o que nos leva a pensar que a obra de Homero permaneceu inalterada por duzentos anos?

Temos ainda que levar em consideração a declaração de Zogić. Ele afirma cantar a mesma canção palavra-por-palavra. Devemos assumir que ele estava mentindo ou que não percebeu as mudanças entre as duas versões? A resposta, segundo o estudioso, é não em ambos os casos. Lord explica que o conceito de palavra-por-palavra é bastante flutuante na tradição oral e que Zogić não pensa estar mudando o texto ao substituir uma palavra por seu sinônimo. Mesmo porque diversos cantores declararam à Lord que "mudar é ruim". Concluímos, portanto, que na tradição oral, para que seja considerada como tal, uma mudança deve ser muito mais profunda, alterando, por exemplo, elementos do enredo.

Devemos agora mudar um pouco nosso enfoque e retornar ao século XVII quando uma enorme discussão sobre os erros e inconsistências do texto homérico foi lançada. Uma série de pesquisadores passou, então, a atacar a autoria dos textos homéricos afirmando que eles não eram obras de um único autor conforme esperam nossos conceitos modernos, mas sim, uma unificação de uma série de poemas esparsos que foram aos poucos sendo acoplados uns aos outros. Segundo essa abordagem Homero não foi o compositor de seus poemas, mas sim um coletor de poesias que já existiam espalhadas por toda a Grécia e que teriam sido metamorfoseadas por ele em uma única grande obra.

Os separatistas, conforme foram nomeados, possuíam alguns bons argumentos reservados para si. Seu primeiro bom argumento é o de que o texto homérico é escrito em uma linguagem muito particular que se convencionou chamar dialeto homérico. Esse 
dialeto, embora majoritariamente jônico, é um emaranhado de influências de diversos dialetos de diversas regiões da Grécia, e nele encontramos ainda o uso de arcaísmos de diversas épocas.

O que esse amálgama de dialetos significa em termos práticos? Bom, se consideramos que a Ilíada e a Odisséia são mosaicos constituidos de vários poemas independentes, faz todo sentido que em toda a obra exista uma forte heterogeneidade lingüistica. Lord lembra, no entanto, que ao imaginarmos um Homero erudito, fluente em vários dialetos e conhecedor de arcaísmos de várias épocas, que intencionalmente resolve escrever um poema influenciado por todo esse material lingüístico, corremos o risco de cair em anacronismo. A figura do autor erudito, conhecedor de várias linguas, valeria quando pensamos em Dante que declaradamente usou várias línguas (latim, francês, grego) e vários dialetos (quatorze, que vão do Toscano ao Bolonhês) na composição da sua Divina Commedia. Esperar o mesmo tipo de comprometimento literário de Homero, segundo Lord, seria um erro metodológico.

O segundo bom argumento da linha teórica separatista vem de uma série de eventos narrados na Ilíada e na Odisséia que parecem destoar daquilo que foi narrado em outros momentos. Pensa-se em trechos como o Catálogo das Naus, na Ilíada, que parece mais um catálogo de relevância histórica do que uma narrativa épica efetiva. O próprio Havelock trabalha com essa hipótese ${ }^{7}$ considerando que esse trecho inicialmente não fizesse parte do poema e que foi anexado por motivos enciclopédicos. ${ }^{8}$

Os separatistas têm outros exemplos de trechos adicionados $a$ posteriori como, por exemplo, a descida dos pretendentes ao Hades, na Odisséia. No entanto, os exemplos caem um pouco de qualidade, uma vez que as diferenças entre as cenas e o todo da narrativa dificilmente são tão contrastantes quanto no caso do Catálogo das

\footnotetext{
${ }^{7}$ HAVELOCK, op. cit., cap. 3.

${ }^{8}$ Segundo Havelock, o conhecimento enciclopédico (por exemplo, saber quantos guerreiros e barcos participaram da guerra de Tróia) era parte inalienável da educação do jovem grego.
} 
Naus. Justamente por isso, os separatistas começaram a 'recortar' os poemas de diferentes formas, discordando, porém, sobre quais cortes seriam autênticos e quais seriam falsos. Foi assim, diz Lord, que os separatistas causaram o descrédito de sua própria teoria.

Antes de continuarmos a desenvolver as idéias que concernem a esse grupo de estudiosos e seu envolvimento com o Kalevala, discorro rapidamente sobre uma outra abordagem que, segundo Lord, evitou os extremos dos unitaristas, que enxergavam Homero como um erudito, e dos separatistas, que chegaram a negar a existência de Homero. Essa terceira linha teórica, defendida pelo estudioso, considera o texto homérico como literatura oral efetiva e viva, passível de mudanças constantes até o momento em que o texto foi congelado ao ser escrito e, aí sim, se tornar canônico e irretocável. Segundo essa teoria Homero não foi o criador completo dos poemas, no sentido de que ele, e só ele, inventou personagens, enredo, versos etc. Ao contrário. Homero seria um continuador da arte oral: os poemas já existiriam e seriam repassados de boca em boca sofrendo diversas mudanças de linguagem, de enredo, de extensão etc. Homero teria sido então o melhor, o maior e o último desses cantores, alguém que teria revisado tudo aquilo que chegou até nós. Isso explica, por exemplo, a influência de diversos dialetos. Imaginemos o poema sendo transmitido oralmente por bardos de diversas origens: um de Esparta, outro de Mileto, outro ainda de Atenas. Faz sentido que cada um deles tenha influenciado o poema com aspectos específicos de seu dialeto. E, se formos mais longe, supondo que esses bardos são cada um de uma geração diferente, faz sentido que os termos empregados sejam modificados pouco a pouco. Porém, mesmo com o vocabulário mudando e se atualizando constantemente, é igualmente válido considerar que algumas palavras se congelassem e que mesmo que já tivessem desaparecido a décadas do uso comum, ainda estivessem preservadas nos poemas de Homero. Lord nos ajuda nesse último ponto quando constata, através de entrevistas, que vários cantores épicos iugoslavos não sabiam o significado de diversas palavras que empregavam. Eles 
diziam usá-las porque foi dessa forma que aprenderam tal canção. Lord afima, ao fim de sua exposição, que esse direcionamento foi o que melhor deu conta, até agora, da enorme extensão lingüística dos poemas.

Voltemos, porém, à primeira linha teórica apresentada pelos separatistas. Esses pesquisadores, e toda a controvérsia que causaram, foram de enorme valia não só para os estudos de Homero, mas também para a literatura finlandesa.

As discussões separatistas borbulharam durante todo o século XIX e dois gigantes literários foram concebidos graças às suposições dessa teoria: o Kalevala e o Kalevipoeg. Ambas essas obras são poemas épicos confeccionados a partir de poemas orais esparsos que foram unificados, por assim dizer, em 'laboratório'. As obras foram escritas, respectivamente, em finlandês e em estoniano, línguas aparentadas (fino-úgricas) que, na época, possuíam um ciclo de poesia épica oral muito vivo.

O Kalevala foi compilado pelo erudito Elias Lönnrot (1802-84) que inicialmente não pretendia escrever um épico, mas sim, se preocupava em coletar e armazenar a poesia oral da época temendo que ela se perdesse. Ele fez onze viagens de coleta por toda a Finlândia que resultaram em diversas antologias poéticas. No entanto, com o tempo, Lönnrot concebeu a idéia de escrever um épico a partir do material coletado e, por isso, alterou o direcionamento de seu trabalho. Nesse período, vale dizer como nota, a Finlândia havia apenas se livrado de séculos de dominação sueca (a língua oficial do país ainda era o sueco) para ser dominada em seguida pelos russos. Os finlandeses, conseqüentemente, encontravam-se em uma situação delicada no que dizia respeito à sua própria língua e cultura. Nesse panorama o projeto de Lönnrot foi recebido com entusiasmo e ele foi considerado como um dos grandes responsáveis pelo "acordar nacional", movimento de libertação que culminou com a expulsão dos russos e independência da Finlândia em 1917. Hoje, para se ter uma idéia do impacto que o poema 
causou, o 28 de fevereiro, dia da publicação do Kalevala, é feriado e é considerado motivo de comemoração nacional.

\section{O Kalevala}

O Kalevala é um poema épico de 22.795 versos aliterados e divididos em cinqüenta cantos ou runos, termo que em finlandês quer dizer 'poema'. O poema narra a história do povo finlandês, começando com o primeiro ser humano e terminando com a chegada do cristianismo às terras fínicas. $O$ próprio título já deixa a temática evidente: Kalevala significa, em finlandês, "Terras de Kaleva (Finlândia)".

O poema se estrutura em torno de heróis cujas peripécias são organizadas em ciclos de um modo simile ao que acontece na Ilíada e na Odisséia. Na Ilíada, por exemplo, temos o ciclo de feitos heróicos de Diomedes, de Heitor, de Aquiles, entre outros, enquanto que, na Odisséia, os quatro primeiros cantos compõem a Telemaquia, o ciclo dedicado ao filho de Odisseu, Telêmaco.

No Kalevala, são quatro os principais heróis: Väinamöinem, semi-deus, primeiro homem, protetor da Finlândia, bardo, mago, médico, etc.; Lemminkäinen, um belo e arrogante jovem que é de certa forma uma mistura de Aquiles e Don Juan; Ilmarinen, ferreiro imortal que é capaz de forjar qualquer instrumento e que cria o sampo, motivador de grandes batalhas na narrativa; Kullervo, o herói trágico da narrativa, que se suicida ao descobrir que uma desconhecida com a qual havia mantido relações era, na realidade, sua irmã.

Os ciclos heróicos são alternados e divididos, pode-se dizer, aleatoriamente. Os dez primeiros cantos, por exemplo, constituem o primeiro ciclo de Väinamöinem; os cinco seguintes, o primeiro de Lemminkäinen; nos cantos de dezesseis a dezoito, temos o segundo ciclo de Väinamöinem; e de dezenove a vinte e cinco temos o primeiro ciclo de Ilmarinen; e as divisões continuam. 
São, porém, as características formais do Kalevala que despertam maravilha. Qualquer estudioso de literatura não pode deixar de ficar muito surpreso com o esquema de versificação do poema: os versos são todos tetrâmetros trocaicos, o que significa que são formados por oito sílabas poéticas e que as sílabas ímpares são fortes e as pares são fracas. Além disso, os versos são aliterados. A aliteração é a repetição de uma mesma consoante nas sílabas fortes do verso. De certa forma, a aliteração é o oposto da rima, uma vez que a rima ocorre no fim das palavras, enquanto que a aliteração ocorre no início e, ambas, são condicionadas pelas tônicas. Línguas que tendem a acentuar o final das palavras formando oxítonas e paroxítonas (português, francês, italiano) rimam com mais facilidade. Já as línguas que tendem a acentuar o início das palavras (inglês, alemão) aliteram com maior facilidade. Eis um exemplo do Runo 40, versos 257-262, na tradução de Crawford (as aliterações estão marcadas em negrito e os pés troqueus entre barras):

\author{
Vaka/vanha/Väinä/möinen \\ käski/ nuoren/, käski/vanhan, \\ käski/keski/kertai/senki \\ soitta/mahan /sormi/llansa \\ tuota/ruo/taista/romua, \\ kalan/luista/ kante/letta.
}

Wainamoinen, ancient minstrel,

Let the aged try the harp-strings,

Gave it to the young magicians,

To the dames and to their daughters,

To the maidens, silver-tinselled,

To the singers of Wainola.

Sublinho o fato de que o verso käski keskikertaisenki é uma jóia literária: o mesmo som ecoa seis vezes, três aliterações (nos tempos fortes) e três consonâncias (nos tempos fracos). A partir desse 
exemplo pode se ter uma idéia do quão magnânima é a tessitura lingüística do poema.

As viagens de coleta feitas por Lönnrot começaram em 1827 e se estenderam por um período de quinze anos. Sua idéia inicial era preservar os poemas orais, registrando-os por escrito. Com esse horizonte à sua frente ele publicou diversas antologias de poemas, como o Kantele (1829-1831) e o Kanteletar (1840), e de provérbios, como o Sananlaskuja (1842). Vale chamar a atenção para o fato de que todos os poemas e provérbios oriundos da tradição oral finlandesa são elaborados no mesmo verso, o tetrâmetro trocaico aliterado. Isso se dá porque é típico da tradição oral ter um único verso como possibilidade de composição poética. Em The Singer of Tales, Lord discorre longamente sobre o tema e demonstra como o verso grego (hexâmetros datílicos) e o iugoslavo (tretâmetros trocaicos com uma cesura obrigatória na quarta sílaba) são igualmente congelados. ${ }^{9}$

Ao contrário dos outros textos, o Kalevala não foi unicamente coletado: ele é o resultado de uma mistura entre diversos poemas que foram unificados por Lönnrot. Ou seja, Lönnrot se deu ao direito de modificar os textos omitindo versos, acrescentando outros de sua autoria, modificando o enredo, alterando a ordem dos fatos, enfim, fazendo todas as mudanças necessárias para que o texto final se mostrasse como um todo coerente. Estima-se que 33\% dos versos do poema sejam resultados diretos da coleta não tendo sofrido qualquer modificação; que $50 \%$ dos versos tenham sofrido pequenas alterações; que $14 \%$ tenham sido criados por Lönnrot a partir de variações coletadas; e que apenas 3\% sejam invenções dele. ${ }^{10}$ Esses dados variam um pouco de acordo com certos críticos, mas a contagem dos versos efetivamente criados por Lönnrot sempre se

\footnotetext{
${ }^{9}$ HAVELOCK, op. cit., cap.4.

${ }^{10}$ LEINO, Pentti. The Kalevala Metre and its Development. In: Songs Beyond the Kalevala, Transformations of Oral Poetry. Studia Fennica Folkloristica 2. Helsinki, pp. 56-74.
} 
restringe a algo em torno de $3 \%$ a $5 \%$ do todo do poema. Isso significa cerca de 1.140 versos, na melhor das expectativas.

A primeira edição do Kalevala veio a público em dois volumes em 1835 e 1836, oito anos após terem começado as viagens de coleta, e contava com 12.078 versos divididos em 32 cantos. A segunda e definitiva edição veio à luz somente em 1849, vinte e dois anos após o início das viagens de coleta, e aí sim contava com todos os 22.795 versos divididos em cinqüenta cantos. É importante sublinhar que o Kalevala foi imediatamente recebido como o épico nacional e que ele lançou uma febre sobre o mundo acadêmico que se debruçou abruptamente sobre a cultura finlandesa oral. Nas artes, vários foram os artistas que pagaram tributo ao Kalevala, entre eles o pintor Akseli Gallen-Kallela (1865-1931) que ilustrou diversos trechos do poema, sendo o mais conhecido de seus quadros "A defesa do Sampo" (Sammon puolustus - 1896), e o compositor Jean Sibelius (1865-1957) que produziu várias peças baseadas no épico, sendo uma das mais famosas o poema sinfônico "Kullervo Op. 7" (1892).

\section{Kalevala e o problema homérico}

Agora tento responder à pergunta: como pode um épico produzido no século XIX, em finlandês, aproximar-se dos poemas gregos que datam aproximadamente de IX a.C. e em que medida tudo isso pode relacionar-se com problema homérico?

Creio que o Kalevala poderia ser usado como uma espécie de banco de dados que serviria para avaliar se as propostas dos separatistas são viáveis e comprováveis.

Uma série de estudiosos clama que Homero não compôs a Ilíada ou a Odisséia, mas sim, unificou diversos poemas que já existiam esparsos por toda a Grécia. Um outro grupo prefere ver Homero como o continuador de uma linhagem que já existia antes 
dele e, assim, também nega que ele tenha criado seus textos, pelo menos do modo moderno de se conceber 'criação'. ${ }^{11}$

É possível, ainda, pensarmos em uma combinação das duas propostas: alguém unifica vários poemas, elabora com eles uma obra só e cria uma linhagem de transmissão oral que modifica o texto no meio do caminho e, ao final, acaba desembocando em Homero ${ }^{12}$.

$\mathrm{O}$ caso é que o primeiro grupo de separatistas recortou insistentemente os textos tentando encontrar os poemas inicialmente unificados por Homero, a matéria-prima de que ele teria lançado mão. E, segundo Lord, não obtiveram sucesso em sua empreitada.

Agora, e se fizéssemos isso com um texto que declaradamente foi unificado? Lönnrot foi o primeiro a dizer que não escreveu o Kalevala e que o épico é o resultado da unificação de diversos poemas orais. Ele não apenas publicou o resultado da unificação dos poemas, como também lançou em antologias, em seu formato original, os poemas de que fez uso. Não contente, ele ainda publicou um Kalevala de meio de caminho, um esboço do texto definitivo que estava por vir.

Assim, enquanto que em Homero temos de supor, teoricamente, a partir do resultado final, quais seriam os textos usados inicialmente, em Lönnrot temos à nossa disposição o início, o meio e o fim do processo de unificação e passamos então a lidar com dados que não se limitam à esfera do provável, mas, ao contrário, nos dão material para comprovar ou refutar as mais diversas propostas.

Para terminar, sugiro que um estudo atento das técnicas de unificação utilizadas por Lönnrot pode lançar certa luz nova a esse gênero de estudo homérico, mesmo que ao fim a conclusão possa ser: "o Kalevala foi criado sob condições diferentes e, portanto, não serve para apontar conclusões aos textos homéricos".

Descobertas potenciais dormem com suas faces neutras sob a superfície desse lago finlandês.

\footnotetext{
${ }^{11}$ LORD, op. cit.. Vide introdução da obra.

${ }^{12}$ Idem.
} 


\section{BIBLIOGRAFIA}

BOSLEY, Keith. The Kalevala. New York: Oxford University Press Inc., 1999.

CRAWFORD, John Martin. The Kalevala, the Epic Poem of Finland. 1888. Disponível em:

http://www.gutenberg.org/dirs/etext04/kale210.txt. Data de acesso: 09/09/08

HAVELOCK, Eric. Prefácio a Platão. Trad. Enid Abreu Dobránzsky. Campinas: Papirus, 1996.

LEINO, Pentti. The Kalevala Metre and its Development. In: Songs Beyond the Kalevala, Transformations of Oral Poetry. Studia Fennica Folkloristica 2. Helsinki, pp. 56-74.

LORD, Albert B. The Singer of Tales. Cambridge: Harvard University Press, 1960. 